\title{
FROM ONE ISLAND TO ANOTHER - MIGRANT WORKERS FROM THE PHILIPPINES LIVING AND WORKING IN GERALDINE, NEW ZEALAND
}

\section{Tessa Lee, Gemma Hooton, Olivia Hyslop, Hinemoa Julien, Maia Love-Williams, Amy McCarthy, Natasha Moore, Stella Murchie, and Laurie Mahoney}

No man is an island, entire of itself; every man is a piece of the continent, a part of the main.

John Donne (1624)

\section{INTRODUCTION}

Citing John Donne's poem, hbgelett's (20.2.20 I8) blog refutes the idea that people can be an island metaphorically. He claims that "[These] island metaphors suggest that people, thinking, and knowledge are not isolated or separate. They are all interconnected, just like everything else". Albeit, both hbgelett and Donne are referring to the reliance humans have on a spiritual world or 'god'. It is the claim of the authors of this article, that they refute hbgelett and Doone and offer an alternative claim, that being, when people are isolated from their culture and are in a minority, they can be considered as an island. The Filipino migrants living in Geraldine are often working on farms (geographically isolated), which are run by New Zealanders (culturally and socially isolated) and can therefore metaphorically be considered as an island.

Geraldine or Heratini, is a small town in the South Canterbury region of the South Island of New Zealand. It is about $140 \mathrm{~km}$ south of Christchurch, and inland from Timaru, which is $35 \mathrm{~km}$ to the south. A team of nine third year Bachelor of Nursing learners undertook a community partnership project with professionals from the Heratini area in August 2021, building on a project conducted in 2017 by previous nursing students on the Heratini District. In the former project, two health needs were identified: migrant health and HPV immunisation. An impact analysis of the former project was undertaken in 2021 and the community stakeholders identified continued concern for the health of the migrant population of Heratini.

The current project, focused on the migrant population in Heratini in particular, the Filipino workers employed in the dairy industry. The learners identified medication compliance and access to health care were the main ongoing concerns for migrant workers and they created resources for the local health workforce to use to support Filipino workers.

The one thing in common that New Zealand and the Philippines has, is that both countries are archipelagos (islandbased) in the Pacific region. This article contrasts relevant statistics between these two island-based countries and will then discuss a project that 3rd year Nursing students presented for their community health placement, when their population aggregate for a community health development project focused on the migrant (mainly Filipino) workers in Geraldine, New Zealand. 


\section{PART ONE}

\section{Migrants}

Geographically, islands are a piece of land surrounded by water. Metaphorically people can be considered as islands when they are separated or isolated from others, in this instance Filipinos in New Zealand are separated from the Philippines and their culture. They are a minority. Hence, Filipinos in New Zealand can be considered as "islands" from a metaphorical perspective.

The Philippines is the 13th most populous country in the world with a population of $1 \mathrm{I}$ I,464,904 million, with a median age of 25.7 years; compared to New Zealand's population of 4,872,317 and a median age of 37.4 (www. worldometers as of 6/10/202I). Both countries are island based and of similar sizes. According to NZ Stats (202I) there are 72,612 Filipinos living in New Zealand which is the third largest Asian population group in New Zealand. Most Filipinos come here to undertake study, work in health care or in business (Immigration NZ, 202I), and more than 20\% of Asian peoples living in New Zealand being born here (NZ Stats 202I). There are up to 187 different languages spoken in the Philippines, with Tagalog Cebuano and English being the official language, while in New Zealand English, Te Reo and Sign are the official languages (Wikipedia).

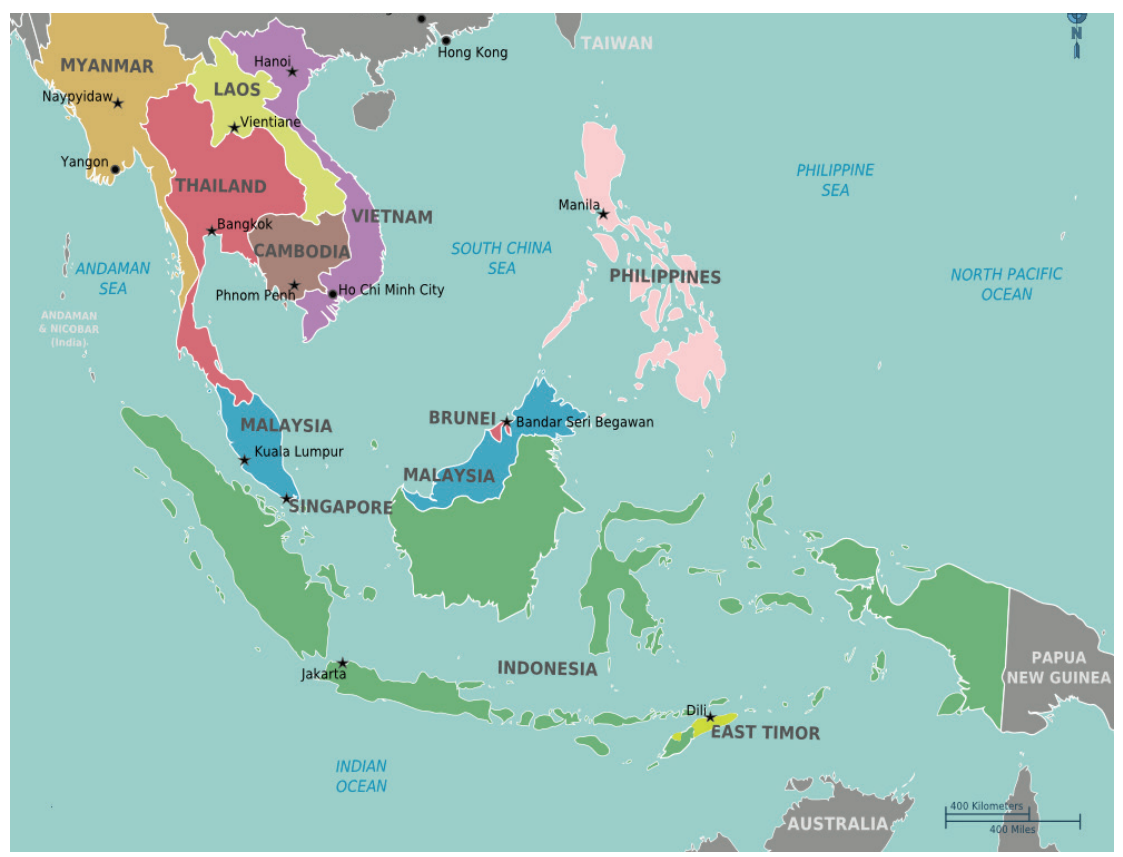

Figure I. Philippines Source: Map of South East Asia.png - Wikimedia commons

Dairy farming in New Zealand is a key export industry that is often closely linked to the national economy yet is dependent on a substantial labour force of work visa holders who have limited rights and who have very narrow pathways to citizenship (Collins \& Bayliss, 2020). Collins and Bayliss (2020) looked at temporary migration and the stereotypes of migrants created by nationalism on dairy farms. Dairy farming is one of the main occupations for many Filipino migrants living in Heratini. In 2018/19, 50.7\% of work visas issued for dairy farming were issued to Filipinos with $91.7 \%$ of dairy farm visa holders identifying as male. 


\section{Heratini}

Heratini is in the Timaru District of South Canterbury. Heratini has an ethnic mix including European, Māori, Pacifika, Asian, and others (Table I). Europeans make up most of the population, with $94.7 \%$ identifying as European in the 2018 census (Statistics New Zealand, 2018). English is the most common language spoken, followed by Te Reo.

Table I. Ethnic groups in Geraldine Source: Statistics New Zealand (2018)

Ethnic groups for people in Geraldine, 2006-18 Censuses

\begin{tabular}{|l|l|l|l|}
\hline & $\mathbf{2 0 0 6}$ (\%) & $\mathbf{2 0 1 3}$ (\%) & 2018 (\%) \\
\hline European & 85.2 & 95.4 & 94.7 \\
\hline Māori & 5.9 & 5.2 & 7.2 \\
\hline Pacific peoples & 0.6 & 0.8 & 1.0 \\
\hline Asian & 0.9 & 1.2 & 2.3 \\
\hline Middle Eastern/Latin American/African & 0.3 & 0.6 & 0.7 \\
\hline Other ethnicity & 13.4 & 2.6 & 0.9 \\
\hline
\end{tabular}

The agricultural industry is the heart of Heratini's economy, with a substantial increase in dairy farms over the region in the last 20 years. The core forms of agriculture involve agricultural crops, dairy farming, and rearing of livestock.

\section{Migrant Population in Heratini}

The migrant population in Heratini can be defined as individuals and families who are living in Heratini on a temporary basis for work purposes. In the 2018 census, 1.4\% of the Heratini population had lived overseas one year prior to the statistics being taken (Statistics New Zealand, 2018). 13\% of the population had been in Heratini for 5-9 years since their arrival. Although Tagalog is the official language if the Philippines there are over 120 languages spoken there. English is an official language and is commonly spoken there.

In 2015/16, 1,772 people found employment as permanent migrants (Skilled Migrant Category principal applicants) in the Canterbury region (Immigration New Zealand, 2017). The Philippines, India, and the United Kingdom were the most source countries. 7,204 people were approved for the Essential Skills work visa in Canterbury. The Philippines and India were the two most source countries, with livestock farmers being the main occupations of Essential Skills workers in Canterbury in 2015/16 (Immigration New Zealand, 2017).

\section{Needs Analysis of Migrant Workers}

The learners completed a SWOT (strengths, weaknesses, opportunities and threats) and needs analyses of the migrant community in Heratini and found the following issues:

A lack of spaces in General Practitioners Services because the practices were fully enrolled, cost of appointments due to visa restrictions, a lack of routine screening, a lack of health services for migrants including COVID vaccinations and mental health services. Other issues the learners identified were medication adherence, hypertension, and Diabetes. Medication compliance and access to health care were the two issues this group of learners considered that they could analyse further. 


\section{PART TWO}

\section{Medication adherence}

Ethnicity and cultural background are intertwined with medication adherence with Filipinos having the lowest adherence rate to prescribed medication compared to other ethnicities, particularly those in the 18-39-year age group which many of the Filipinos in Heratini includes (Taira et.al., 2007, Villanueva, 2013). Additionally, Shahin et al. (2020), found that education level is significantly associated with medication adherence in migrant populations. This is significant when Filipino individuals are more at risk of developing cardiovascular disease (Taira et al., 2007). Other key factors that influence adherence were perceptions of illness, personal control over illness, and coherence. Migrants who felt they had control over their illness and positive perceptions about treatment options had increased medication adherence.

In New Zealand, barriers for medication compliance in new migrant group includes financial barriers such as paying for GP visits and medication, lack of affordability to purchase over the counter medications, problems with family sharing prescribed medications, misconceptions due to language barriers, not understanding information such as why they are taking medication and when (Babar, Pengelly, Scahill, Garg, \& Shaw, 2012; De Guzman et.al., 2013).

De Guzman et al. (2013) explored factors influencing medication adherence in the elderly Filipino population taking medications prescribed for chronic illnesses. The elderly Filipino population typically has a lower adherence rate than younger generations (De Guzman et al., 2013). De Guzman et al. (2013) discusses the ways adherence to medications could be improved for this population, including increased trust of prescribing physicians, satisfaction with the consultation, and event-based memory tasks such as developing routines. De Guzman et.al (2013) also explained that older Filipino's believe prescribed medications are a cure for the condition, rather than as a preventive for further complications or worsening of the condition. For Filipino migrants living in New Zealand this could potentially be a major barrier in medication adherence as any relationship with a physician is based on a shortterm intervention. An important function of the healthcare team is to provide an environment that establishes optimal patient-physician communication or develop a trusting relationship with the prescribing physician. This is a challenge as there may be barriers to effective communication for Filipino migrants visiting New Zealand GPs, including language barriers, cultural differences, and appointment time limits.

Ethnicity has an important role in facilitating or hindering access to primary health care in New Zealand, and as a result, new policies to address these challenges are advised. A lack of familiarity with New Zealand's medication laws can lead to a mistrust or lack of understanding in the health system, becoming yet another barrier for migrants. This barrier for migrants prevents them from taking advantage of community services and exemption cards, which are intended to help them settle here (Babar et al., 2012). The authors contend that the lack of trust or understanding in the New Zealand primary health care system, may be another reason why migrants may consider themselves isolated from health services, and see themselves in a similar way to that of an 'island'.

Additionally, lower levels of education and ethnic backgrounds, limits awareness about western medicines. According to a study conducted in Auckland to assess consumers' knowledge, perceptions, and attitudes about medicines it was noted that a lack of culturally relevant treatments is a barrier to receiving services, which they believe contributes to Chinese patients' low levels of involvement with oncology treatment programs (Twarog \& Kapoor, 2004).

Babar et al. (20I2) concurs with Twarog and Kapoor, with a study exploring attitudes, beliefs, and perceptions of a cohort of migrants about medicine access and use in New Zealand. They identified several barriers in migrant health. First, the lack of availability of traditional medicine in New Zealand, with many Asian migrants believing that Western remedies are seen as pseudoscience. Second, the barrier of language and culture, which includes, understanding referrals processes, primary v's secondary care, and availability of subsidies on certain medications in 
New Zealand. Finally, some migrant's perceptions regarding the use of medication were inaccurate, with migrants believing in sharing medications with others when they first arrived in New Zealand. Two reasons offered by migrants sharing medications were the cost of visiting doctors and pharmacies to obtain medications, and because they are unaware of government subsidies. If all medication is equally priced (prescribed versus over the counter), they were concerned about using up all the medication at home before buying new ones, even if the medication is the wrong strength or not the correct prescription.

\section{Nursing Recommendations}

I. Utilising a medication chart with clients to promote control and positive perceptions about treatment

2. Provide pamphlets in Tagalog about health conditions to enhance understanding and adherence

3. Provide information about health-lines and support services

The learners created a tear-off pad (Resource I below) for use by Pharmacists when dispensing medication, reminding clients when prescription medications should be taken. The client can tick off when they take their medications. This was uses both English and Tagalog for Filipino migrants to use. An additional pamphlet on managing hypertension was also created and translated into Tagalog. This has been shared with the local health services.

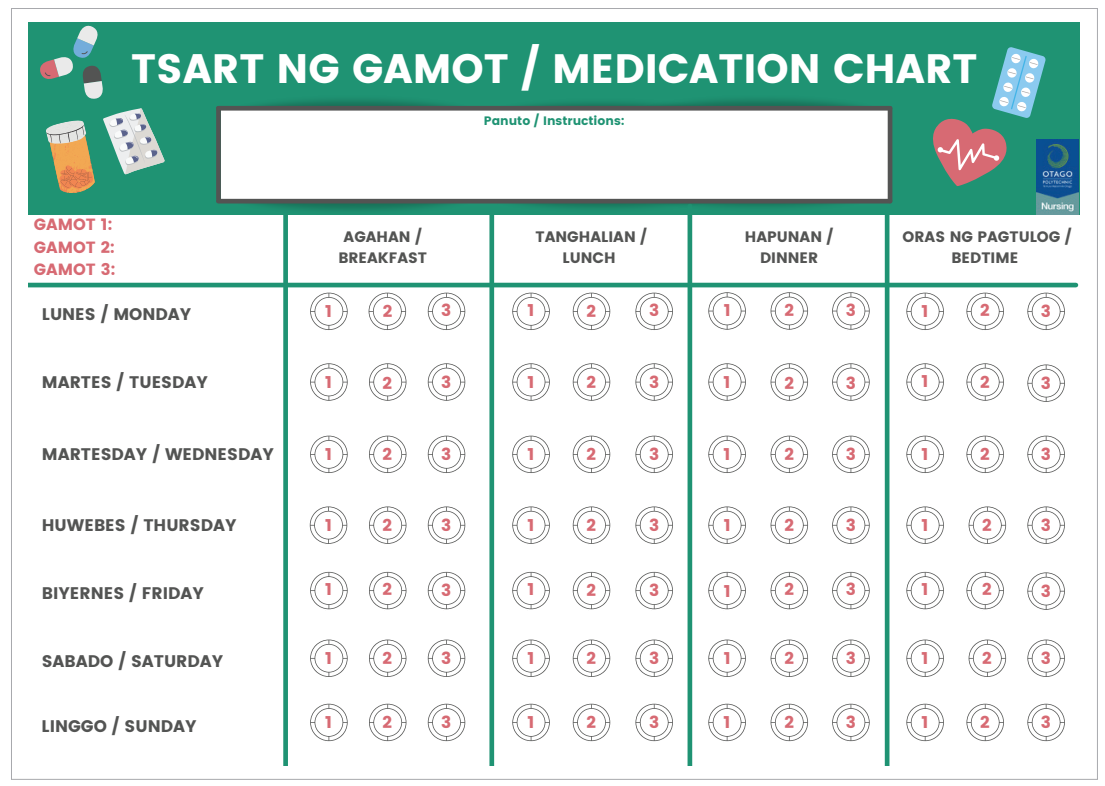

Figure 2. Medication chart. Source Authors.

\section{Barriers to access health care}

The authors indicated why Filipino migrants found engaging with the New Zealand healthcare system challenging. They identified the following as barriers to health care in New Zealand; Language barrier, culture constraints difference in cultural views, poor health literacy, a lack of knowledge about accessing healthcare services in New Zealand, poor experiences with healthcare services, divergent understandings of health and the extent of local support networks and legal/visa restrictions - causing racial stratification and workplace inequalities. The barriers give way for enablers to be created for Filipinos to access and benefit from NZ healthcare services 


\section{Legal barriers}

Dairy farming in New Zealand is a key export industry that is often closely linked to the country's economy yet is dependent on a substantial labour force of work visa holders who have limited rights and who have very narrow pathways to citizenship (Collins \& Bayliss, 2020). A temporary migration regime excludes labour migrants from universal rights that are otherwise offered to workers - freedom to change employers, to seek welfare or health support, or to build a family (Anderson, 2008). This reinforces the concept that the Filipinos are isolated from health services and can be considered an island within New Zealand.

Temporary migration is based on the provision of limited rights to migrants, which is a kind of civic stratification (Collins \& Bayliss, 2020), limiting the possibilities, length of stay, and rights granted to migrants, as well as the prospect of integration through residence and citizenship. In this sense the Filipino migrants in New Zealand can be considered politically isolated island. Temporary visa holders' rights are restricted. For example, they have restricted access to healthcare (maintaining the metaphor of migrants as an island), and are bound to a single employment, which has a substantial influence on migrants' well-being and the embodied experience of migration (Collins, 2019). The negative consequences of temporary status illustrate how civic stratification and denial of rights work to keep migrants on the outside of society and limit their opportunities for advancement (Rajkumar et al., 2012), or can be seen as a socially isolated island.

\section{Health service barriers}

As migrants began the move to another country their health is considered 'good', although the wellbeing of the migrants is seen to gradually deteriorate as various barriers such as restrictions to health services, cultural and language barriers, lack of health insurance, and poor knowledge of the health system within New Zealand (Kanengoni et al. 2018). Language is a significant barrier that many migrants face, not only for the knowledge of healthcare services available, but it also impacts on health considerably as information from healthcare workers is often not understood by the migrants' accessing healthcare. Health literacy is an important component to any individual's health as it is important for patients to understand various conditions, medications, and ease of access to services required (Kanengoni et al., 20 I8). Additional communication support for migrant workers is an enabler, for instance access to timely interpreters. The importance of interpretation services gives migrant workers a voice within the care received, helping migrant workers to understand health issues, and relevant information on medications (Montayre Neville and Holroyd, 2017).

Montayre, et.al., (2017), looked at the experiences of Filipino migrants adjusting to living in New Zealand, wo identified multiple challenges for Filipinos while engaging in healthcare services. The key challenges were, lack of knowledge of the nature of health services (low health literacy), language barriers, and differences in cultural views towards healthcare. Accessing health services and having good health literacy is important as they both support a person's health and wellbeing; however, some Filipino migrants have low health literacy and the lack of knowledge about the New Zealand health system and social services, contributes to underutilisation of services available (Montayre et al., 2017). Low health literacy is associated with poorer health outcomes, lack of engagement with healthcare providers, decreased compliance with medication, and lack of knowledge about managing medical

\section{Health beliefs/perspectives and systems}

Adjusting to a new country creates a barrier as there is a difference in cultural views or practices (culturally isolated reinforcing the sense that a migrant is culturally like an island). Many Filipino migrants identified in Montayre's 2017 study, said their cultural practices were not considered by health professionals. Multiple Filipino migrants stated that in the Philippines it is accepted practice to stay with and be the main carer of the family member in hospital. However, in New Zealand this practice was not upheld in their experiences (with Paediatrics being the exception). 
In the Philippines, it is common for health practices to use herbal remedies and traditional beliefs. However, this contributes to a reluctance or a lack of the willingness for Filipino migrants to access healthcare services in New Zealand (Montayre et al., 2017).

The effectiveness of health systems to promote health and minimise illness is dependent on their accessibility, acceptance, and availability to all parts of society. Some minority ethnic groups in Western countries have limited access to the use of health services, contributing to health disparities (Collins \& Bayliss, 2020). Anderson (2008) investigated migrants' knowledge and their utilisation of New Zealand primary health services. These were influenced by their own experiences with health care systems in their home countries, language difficulties, structural barriers, divergent understanding of health, and the extent of their local support networks. The Ministry of Health (2012) conducted a survey on the Asian populations and reported low use of healthcare services mostly in primary health areas. Further research identified health disparities between Asian migrants and the New Zealand born population, for instance Asian born people have higher rates of tuberculosis (TB), cardiovascular disease, and type 2 diabetes (Anderson, 2008).

The New Zealand primary health care system, particularly general practitioners is complex and a conundrum for many migrants to New Zealand to understand. Anderson's (2008) study showed participants have varied understanding of New Zealand's health care structure. The knowledge of this was influenced by age, time spent in New Zealand, and information provided from friends, family, and health care professionals. Primary healthcare includes assessments and treatment completed by GP clinics, such as antibiotics for infections or illness, medication prescriptions, screening general workups, and diagnoses. Secondary or specialist care is the hospital level system in which patients must be referred by primary care practitioners for specialist assessment and treatment, a process which may have extended waiting times up to 6 months (Ministry of Health, 2012).

This system is in complete contrast to the user-pays system from many Asian countries, where individuals independently seek out the best doctors they could afford (Anderson, 2008). The Philippines has a dual approach of publicly and privately funded health system with primary services only available in large cities. The divergent understandings of the health system in New Zealand, makes navigating the system difficult for many migrants. Ultimately these barriers create in the health disparities for Asian migrants in New Zealand.

With low utilisation of primary health services comes an increased use of the emergency and accident clinics by the migrant population. These A\&E clinics are open after hours and do not have an appointment system, often meaning they are more easily accessible to patients rather than regular centres. Alternatively, 'after hours' services are more expensive than general practice costs.

When understanding the enablers to help migrants navigate the system, Anderson (2008) highlighted the use of community. Simple actions from the community such as clear descriptions of where to go to seek help, costs, and the overall system of New Zealand health care served as successful enablers. Additionally, these can help identify culturally appropriate services for migrants that are going to meet their needs.

Some reasons why migrants experience inequalities when accessing primary health care include, a lack of awareness of the system, previous experience in healthcare, structural barriers and limited access to primary health services resulting in poor migrant health (Anderson 2008). In turn, this increases migrant use of A\&E clinics, as they are often more accessible than regular centres. However, Anderson (2008) also identified enablers that could allow migrants to better navigate the primary health sector. Enablers could be using community support, social networks, and prompting community development in host countries. These will improve the utilisation through culturally appropriate frameworks and further contribute towards reducing health inequalities for migrants. 


\section{RECOMMENDATIONS}

I. Clear health/social service provision policies to create positive migrant adjustment.

2. Providing pamphlets in Tagalog about accessing healthcare/emergency services to support Filipino migrants to access and benefit from New Zealand healthcare services.

3. Knowledge on translation services or apps to overcome the language barrier and increase health education.

To address these recommendations the learners created a pamphlet on the health system (see resource 2 below) and the legal requirements for migrants to access health care, which was also translated into Tagalog. This was shared with the Heratini health professionals.

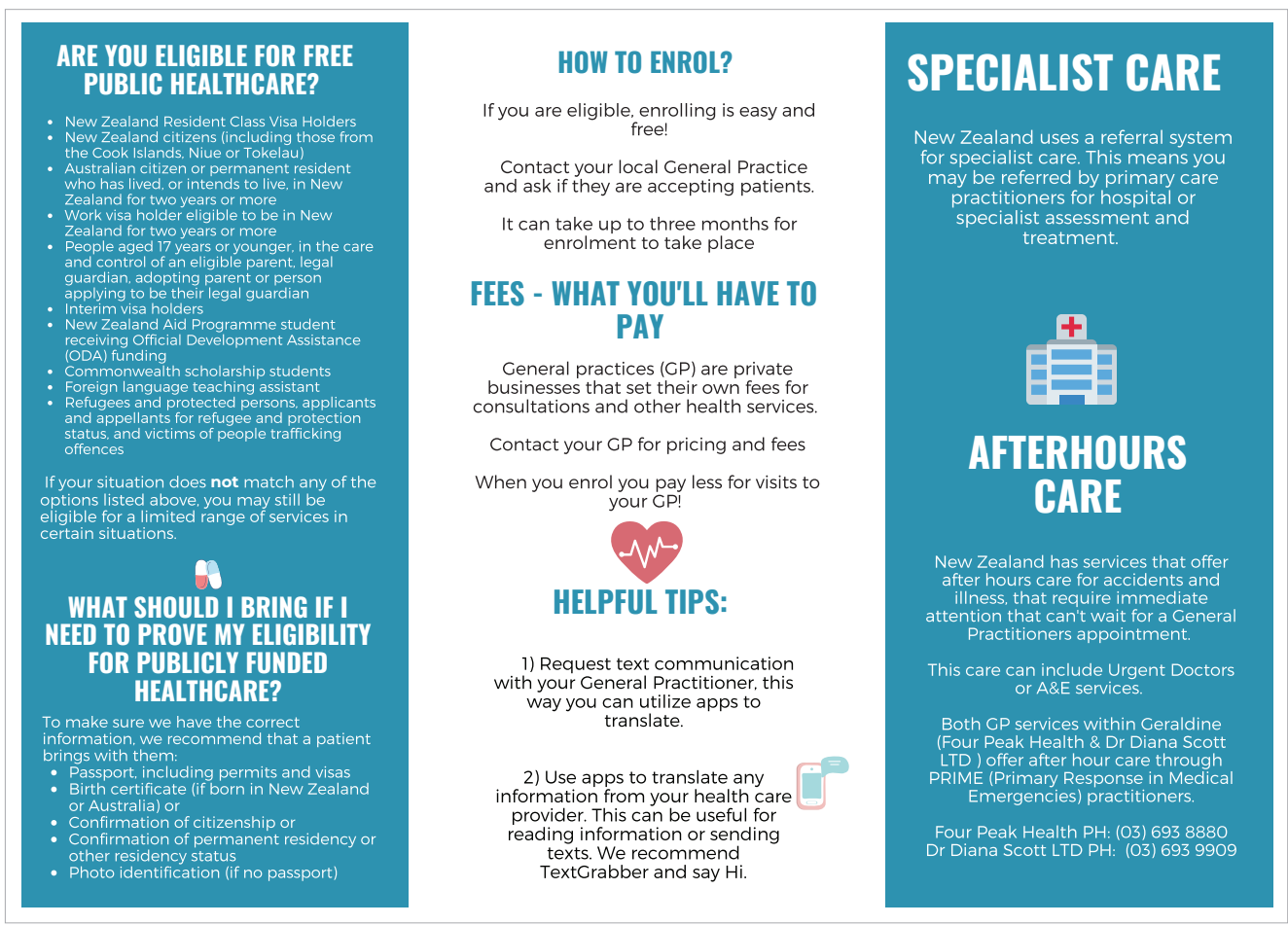

Figure 3. Pamphlet on access to NZ health care. Source: Authors

\section{CONCLUSION}

This project was a continuation of an earlier group of learners who had studied Geraldine as a geographic region for their primary health care paper as part of the Bachelor of Nursing programme. On completion of an impact analysis of that project this group of eight Dunedin based learners undertook a new profile of Geraldine, concentrating on the Filipino migrant community working on dairy farms.

They identified several challenges or barriers that indicate Filipino migrants find while engaging with the New Zealand healthcare system challenging. The barriers give way for enablers to be created for Filipinos to access 
and benefit from New Zealand healthcare services. The barriers suggest a need for clear health and social service provision policies to create positive migrant adjustment. The barriers demonstrate the need for culturally safe integrated and enhanced migrant services that are specific to Filipino people. Providing these services means

Filipino migrants can remain connected to their cultural identity whilst in New Zealand, and thus feel less like an island. If this were the case, then Filipino migrants may not perceive themselves as an island, however, the barriers discussed in the discussion are still evident in New Zealand and migrants are still a minority group who are isolated from their culture. The health promotion resources that the learners created and shared with the community goes some way to reducing isolation and inequities of health care for Filipino migrants and more as part of a clearly defined community of Heratini.

Correspondence to: Laurie Mahoney. Email: lauriemahoneyl8@gmail.com

\section{REFERENCES}

Anderson, A. (2008). Understanding migrants' primary healthcare utilisation in New Zealand through an ethnographic approach. Diversity in Health and Social Care, 5, 29I-301.

Babar, Z., Pengelly, K., Scahill, S. L., Garg, S., \& Shaw, J. (2012). Migrant health in New Zealand: Exploring issues concerning medicines access and use. Journal of Pharmaceutical Health Services Research, 4(I), 4I-49. https://doi.org/l0.1III /j.1759-8893.2012.00105

Collins, F. L. (2019). Anxious desires: Temporary status and future prospects in migrant lives. Emotion, Space and Society, 31, 162-169. https://doi.org/10.1016/j.emospa.2017.10.004

Collins, F. L., \& Bayliss, T. (2020). The good migrant: Everyday nationalism and temporary migration management on New Zealand dairy farms. Political Geography, 80, 102193. https://doi.org/10.1016/j.polgeo.2020.102193

De Guzman, A. B., Guevara, K. I., Guiang, F. J., Gutierrez, A. L., Habaluyas, A. S., Hizon, M. A., \& Idanan, S. G. (20I3). Developing a model of medication adherence among Filipino elderly. Educational Gerontology, 39(5), 298-313. https://doi.org/I0.I080 103601277.2012.661336

Hbgelette blog (21.2.2018) https://hbgelatt.wordpress.com/2018/02/21/no-one-is-an-island/

Immigration New Zealand. (2012). Are you employing migrant dairy farm workers? https://www.immigration.govt.nz/employmigrants/guides/employ-dairy-farm-workers

Immigration New Zealand. (2017). Regional Migration Trends - Canterbury Overview 2015//6. https://www.mbie.govt.nz/ assets/62le33|8c5/regional-migration-trends-canterbury-20I5-I6.pdf

Immigration NZ (2021). The Philippines market. Ministry of Business and Innovation and Employment. https://www.immigration. govt.nz/assist-migrants-and-students/assist-students/international-markets/the-philippines-market

Kanengoni, B., Andajani-Sutjahjo, S., \& Holroyd, E. (2018). Setting the stage: Reviewing current knowledge on the health of New Zealand immigrants - an integrative review. Peerf, 6, e5184. https://doi.org//0.77/7/peerj.5184

Ministry of Health. (2012, July 25). Asian health chart book 2006. https://www.health.govt.nz/publication/asian-health-chartbook-2006

Montayre, J., Neville, S., \& Holroyd, E. (2017). Moving backwards, moving forward: The experiences of older Filipino migrants adjusting to life in New Zealand. International Journal of Qualitative Studies on Health and Well-being, 12(I), 13470 II. https://doi.org/10.1080/17482631.2017.134701।

NZ Stats. (2021). https://www.stats.govt.nz/news/new-zealands-population-reflects-growing-diversity

Rajkumar, D., Berkowitz, L., Vosko, L. F., Preston, V., \& Latham, R. (2012). At the temporary-permanent divide: How Canada produces temporariness and makes citizens through its security, work, and settlement policies. Citizenship Studies, 16(3-4), 483-510. https://doi.org/10.1080/13621025.2012.683262

Shahin, W., Kennedy, G. A., Cockshaw, W., \& Stupans, I. (2020). The role of refugee and migrant migration status on medication adherence: Mediation through illness perceptions. PLOS ONE, 15(I), e0227326. https://doi.org/l0.137//journal. pone.0227326 
Statistics New Zealand. (2018). Geraldine. https://www.stats.govt.nz/tools/20I8-census-place-summaries/Geraldine\#work

Taira, D. A., Gelber, R. P., Davis, J., Gronley, K., Chung, R. S., \& Seto, T. B. (2007). Antihypertensive adherence and drug class among Asian Pacific Americans. Ethnicity \& Health, I2(3), 265-28I. https://doi.org// 0. I080/I355785070I234955

Twarog, S., \& Kapoor, P. (2004). Protecting and promoting traditional knowledge: Systems, national experiences and international dimensions. United Nations.

Villanueva, J. G. (2013). Medication adherence and hospital admissions in Filipinos with cardiovascular diseases. California State University San Marcos. https://scholarworks.calstate.edu/downloads/7p88cg922

Wikimedia Commons: Philippines Source: Map of South East Asia.png - Wikimedia commons

Wikipedia. https://en.wikipedia.org/wiki/Languages_of_the_Philippines

Worldometer. https://www.worldometers.info/world-population/new-zealand-population/ 